Binghamton University

The Open Repository @ Binghamton (The ORB)

The Society for Ancient Greek Philosophy Newsletter

$12-1969$

\title{
The Tradition about Zeno of Elea Re-Examined
}

Friedrich Solmsen

University of Wisconsin-Madison

Follow this and additional works at: https://orb.binghamton.edu/sagp

Part of the Ancient History, Greek and Roman through Late Antiquity Commons, Ancient Philosophy Commons, and the History of Philosophy Commons

\section{Recommended Citation}

Solmsen, Friedrich, "The Tradition about Zeno of Elea Re-Examined" (1969). The Society for Ancient Greek Philosophy Newsletter. 88.

https://orb.binghamton.edu/sagp/88

This Article is brought to you for free and open access by The Open Repository @ Binghamton (The ORB). It has been accepted for inclusion in The Society for Ancient Greek Philosophy Newsletter by an authorized administrator of The Open Repository @ Binghamton (The ORB). For more information, please contact ORB@binghamton.edu. 
The Tradition about Zeno of Elea Ro-exarined

Among students of Greek philosophy there is almost complete unanimity regarding the tenets upheld by Zeno of Elea and the purpose of his treatise as a whole. Although by no means abundant, the verbatin fragments, the second-hand reports about his arguments, and the statements defining his phllosophical intention are considered an adequate basis por definite conclusions. The paper hereby submitted does not ajm at replacing one theory by another but has the more modest objective of examining the evidence on which the communis opinio so confidently rests and to show how mach has been too readily accepted as certain. We shall begin with questions and shall end up not with positive answers but with other questions.

Every comprehensive treatment of Zeno uses as starting point the discussion between Socrates and Zeno at the beginning of Plato's Parmenides (127a6-128e4). This well known section informs us that zono wrote his treatise in defense of Parmenides" thesis and wrote it against the "detractors" of Parmenides. The master had proved है $\nu$ l $\nu \alpha l_{\text {; }}$ the faithruI disciple supported him by proving in each of his arguments (or hypotheseis) is oủu हैor

Plato must know: consensus on this point seems so general that it is almost a sacrilege to question the validity of his "statement"-at least of its substance; some detalls are readily dismissed. Plato, it seems to be hold, was in a position to form a judgment and had no reason for deceivirg his readers; moreover, as Hermann Fränkel has argued, the mixture of jest and seriousness characteristic of Zeno"s reasoning was particularly congental to Plato; therefore he, if anyone, would be in an excellent position to understand Zeno's subtle playfulness. Vlastos and Guthrie refuse to find in Zeno the specific kind of humor which Fränkel has noticed; it may also be asked whether Plato's own humor was not of a more gentle ano amiable kind 
-astelon. Still in principle Fränkel's argument, based as it is on congeniality of temperaments, has more to be said for it than the approach of others who without a moment's hesitation credit Plato with interests typical of a modem historian of philosophy. Yet what Plato in his dialogues reports about his philosophical precursors is almost invariably determined by the specific problem and context for which he refers to them. How onesided, not to say distorted, would be the impression which the dialogues roughly contemporary with the Parmenides would give us of Heraclitus: panta rhei would appear to be the essence of his philosophy. Dealing with Parmenides or the Eleatics as a group, Plato in accordance with the trend of his own argument, treats on some occasions the "one," on others "being" and the rejection of "non-being," on still others the "immovabie" quality of the "one" as the essence of their philosophy (Parm. 128aff.; Soph. 242d; 237aff: Theaet. 180e). Further illustrations would be available but it may suffice to say that Plato's attitude to earlier thinkers is that of a productive philosopher who finds in his precursors whatever suits his ow thought, not at all that of a philological and historical interpreter. Retuming to our section in the Parmenides we may notice some unique features. This time Plato makes as clear as we could wish that Socrates arrives at his conclusions by a process of inference. He proceeds pedetemptim; the steps, i.e. the individual hypotheses, exch of them resting on the preceding, are clearly marked (127e4, the first, would hardly be disputed; $80-10 ; 10-13 ; 128 a 6-b 10)$. Are we then to suppose that Plato had in careful philological analysis formed an opinion about the meaning and purpose of Zeno's work and now uses a peculiar and ingenious device to communicate this opinion to his readers: Socrates inquires of Zeno whether the inferences are correct and Zeno replies by giving an authoritative confirmation. Even granting the truth of these assumpions, 
there would still remain the possibility of an errop on Plato's part. However I have spoken of a device and may thereby approximate the position of N. B. Booth, who (Phronesis 3, 1957, 2) refers to Parmenides and Zeno in this dialogue as "idealized characters," urging us "not to ignore (Plato's) dramatic and philosophical purposes." on this point I should agree with him and shall indeed return to the question of Blato's purpose. For a whlle, however, I wh to proceed along different lines. As we have seon, what Plato says about Zeno's treatise and its purpose is closely related to a corresponding account of Parmenides: the two summaries presuppose and support one another. Now from the fregrents of parmenidos we are in a position to form an independent judgment about his "thesis." Did he actualiy write to prove (as Socrates says, he did "beautifully and well" 128b) हैv E้ $\downarrow \alpha \iota \tau \delta \pi \tilde{\alpha} \nu$, and is this as Plato makes Parmenides himself say (137b3) his hrpothesis? Far from it, and Plato himself, wher it suits his book, 1.e. his argument, knows better. Parmenides established the reality and Indeed the monopoly of Being, $\tau \delta$ Éov, and showed that the only

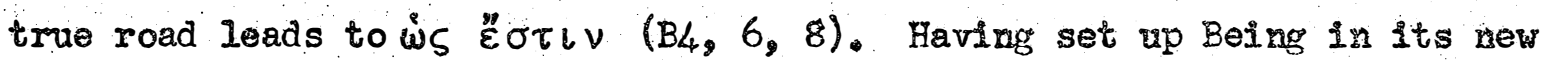
and unheard of glory, he described the semata on the true road (B8.2f providing Being with its essential characteristies. One of then is indead hen (B8.6) another probably (if this is the correct readiag at B8.4) mounogenes, but neither of them occupies a privileged position among the attributes of Being. hen, placed as it is before syneches, is inkely to designate intrinsic unity; if this is the case, orly nounogenes woulo Indicate uniqueness. Certainly, uniqueness is no nore emphasized than say ageneton, anolethron, ovlon, atremes $\left(B 8^{\circ} .3 i^{\circ}\right)$ and more other attributes of Being than it is convenient here to enwarete.

Thus Plato seems to misrepresent parmenides doctrine. Still there may be another facot to the story. If Parmenides only recognizad Being, the "only" may for the next generation of Eleaties have become as important 
as, and in particular more problenatic than, Boing. There is sone ovidence that the issue shlfted. When Empedocles (to say nothing here of Anaxagoras and Leuclppus) transferred some characteristies of Parmenides' Being to his six etornal entities, he il effect gave up the hen. hen or polla, rather than Being or not-Beirg, Being or Becoming may have been the most eagerly debated question of that time. Nso no matter whether Plato knew or merely assured the existence of people who ridiculed Parmenides philosophy (Parm.128c7fr.), it is incringically probable that the hen provoked most attacks-not because of its actual place in the poem but because comon sense would inevitably be most offended by the clains of a monolithic Being which allowed no reality for the innumerable objects of ordinory human experience. Deferders of Parmenides may have found some of their weapons in his ow poen by putting new and stronger accents on what they particulazoly needed, i. perisaps not only on hon and monnogenes but also on his injunction agalnst any now glgnesthai (B8.12), on the pan homojon (3k. 221.), and espoelaliy, one mould think, on his emphatic protest against tro rompha which hwar opinion erroneously posits $\left(8.53 f^{\prime}\right)$. There is indeed monism in his thonghts whether we consider it latent and implied or openiy present. It is close to his "thesis" but it is not the actual thesis. Melissus, who of Pamenides more orthodox followers is best mown to us, still has to eon as his subject (see BIw but also B\%, corsectiy understood) in B7 hen is a predicate of 1 t and as such on the same level as three others (see 7.1); however In B5 and B6 the necessity of 13 sm (still as ar aturibute of Being) is established, and in 37 her (as such?) is wpheld against rival philosophy charpioning ta polla. Quite derinitely tho hen is makng progress.

Melissus, it should be clearly understood, aoes not prove that the thesis Eี 
bination with the other evidence he allows us to belleve that the most acute Eleatic problem of his generation was the alternative: hen or polla. If we see Zeno in this perspective, he may indeed have defended Parmenides but not so much the authentic Parmenides as rather Parmenides' philosophy in the shape which it had taken for thinkers of the next generation. This essential qualification is, as far as I know, never made by the scholars who take their stand on Plato's testimony for Zeno's treatise, nor, what is more important, is it made by Plato himself. For him Parmenides "says hen" (128b3, dl etc.) or $\tilde{\varepsilon} \nu$ to $\pi \tilde{\alpha} \nu$ (128a8). It remains true that to ascribe this doctrine to the historical Parmenides is to get his thought out of focus.

Another assertion of Plato, scil. the $\tau \alpha \dot{u} \tau \delta \nu ~ \lambda \varepsilon \gamma \varepsilon \iota \nu$ of Parmenides and Zeno (128a5, b5; implicite b7ff.) is so closely tied to the statements about Pamenides' hen that it cannot survire as historically valid if the hen is found to be invalid.

Again Plato says that all of Zeno's arguments were designed to refute the polla (127e9ff., 128blf., d2ff.). As we have seen, this testimony could be correct even if Parmenides' own position is incorrectly stated by Plato. Yet on other grounds there is room for doubt. Although the modern interpreters of Zeno are at one in accepting Plato's testimony, when it comes to applying the testimony to the more specific evidence they are less unanimous, and not all make a great effort to have it constantiy in mind. For some it seems to suffice if Zeno's arguments ultimately do away with the "many"; in spite of what Plato affirms not every individual argument must have the "many" for its target. Others regard Plato's statement as Iiterally true and in their interpretation show that with the necessary ingenuity it is possible to find the hypothesis of the "many" everywhere, even in the arguments against motion, refuted. Still 
the prior question may be whether this ingenuity is called for. We do not know Zeno's own wording of the arguments against movement; what Aristotle (Phys. VI 9) reports about them would allow us-in fact make it more natural--to regard movement, not the many as the refutand. In the Parmenides, (if we are ready at all to look at the testimony with critical eyes) we may notice that the step from one argunent of zeno which is fatal to "the many" to a.l1 arguments is taken very fast (12706-10; cf. e10-128al). Moreover-and now we are returning to the subject of Plato's purpose-he has a strong interest of his own in the relation between (the) one and (the) many. Beginning with the Euthyphron and Menon and ending with the Laws this problem engages him again and again; it arises both between forms and particulars and in the realm of Forms themselves and has fully deserved the description in the Philebus (15d7)

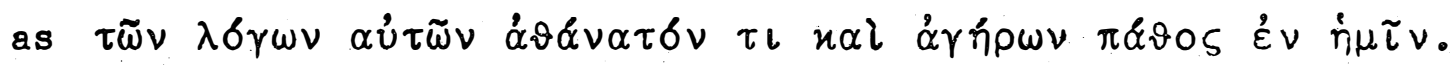
In the latter parts of the Pamenides we follow with bewilderment Plato's experimentation with a great variety of hypotheses concerning the One and the many. Although his interest in these concepts antedates his acdeptance of the Eleatic ontology, he evidently-and with some right-considered it an Eleatic theme, and probably wrote the Parmenides to clarify his own attitude to the alternative "One or many," just as in other dialogues of this period he investigates the Eleatic alternative of Being and non-Being, Rest and Movement. If this was his intentioni. . the "purpose" which we have been urged not to forget-it would be artificial to separate the emphasis on "One" and "many" in the initial section from the later developments of the dialogue. For in doing so we should sever what Plato himself (135ef.) connects.

There remains the most important item of Plato's testimony, his description of Zeno's purpose in writing the treatise. Can this survive 
if so much that is closely connected with it and leads up to it has become problematic? Perhaps it can, although in addition to the suspicions a.lready formulated we ought to consider 1) that Plato embeds this description in a framework of biographical detail worthy of a Hermippus, which is generally discounted and could hardly strengthen our confidence, 2) that as a historian of philosophy Plato qualifies not much better than Aristotle, 3) that the impression he himself gives in Phaedrus 261b-d (esp. d6-8)--a passage on which we shall comment later-- of Zeno's standing and work is rather different from that of the Parmenides and 4) finally that Socrates emphasizes how difficult it is to discover Zeno's intention and finds Zeno agreeing on this point, although he insists on the accidental, not deliberate nature of this difficulty (128bf.). In spite of all these hesitations, Plato's diagnosis may be correct. Zeno even if not directing all his arguments against the "many" may have treated movement and other topics in a manner intended ultimately to bear out Parmenides. Still, if this is the case, Plato's testimony would no longer rest exclusively and primarily on the support he himself provides for it, qualifications and ciarifications would be needed which as far as I am aware no current account of Zeno includes, and we would altogether find ourselves no longer dealing with certainties and established facts but with possibilities capable of more than one interpretation. Having said this much we are perhaps expected to suggest an alternative explanation of Zeno's purpose. For strategic reasons we prefer to postpone such alternative suggestions-which needless to say, would likewise be no more than possibilities. Still one assertion may be ventured even now. There was something puzzling or bewildering about Zeno's treatise; many, if not most, readers were at thej.r wits' end, not knowing what it all meant. We have seen Socrates and Zeno in essence agreeing on this point, and even someone skeptical of other statements in this section 
may have conficence in this hecause if Zeno's intention had been plain and obvious for every reader, Socrates' elaborate inference, his building of hypothesis upon hypothesis would be a waste of time and effort.

But is the testimony of the Parmenides not confirmed by other phases of the ancient tradition about Zeno, and in partjcular by the verbatim quotations from Zeno's treatise which Simplicius has preserved in his commentary on Aristotle's Physics? These verbatim guotations are the most valuable evidence that we have and there is no denying that in two of them we find Zeno doing exactly what Plato leads us to expect of him: he assumes the existence of polla and shows that this assumption entails mutually contradictory results. So far the statements of the parmenides are indeed borne out. The agreement between Plato's "testimony" in the Parmenides and these fragments preserved in Simplicius has probably done much to strengthen the confidence in the former. Yet simplicius, besides having to offer passages of Zeno's treatise in their original wording, also professes to know the content of the entire treatise and the intention in which it was written. This knowledge enables him more than once to pronounce on controversial interpretations of Zeno's arguments. What Simplicius knows about the treatise is again in complete accord with the Parmenides. The agreement could not be closer, but its very closeness is bound to create suspicion, and the suspicion turns into conviction as soon as we place Simplicius' testimony (29A23 $\mathrm{D}_{0}-\mathrm{K}_{0}=\mathrm{In}$ Aristotelis Phrsica 134,3ff.) side by side with that of the Platonic Farmenides:

Plato:

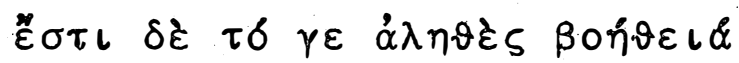
$\tau \iota \varsigma \quad \tau \alpha \tilde{v} \tau \alpha[\tau \grave{\alpha} \gamma \rho \alpha \mu \mu \alpha \tau \alpha] \tau \tilde{\omega}$

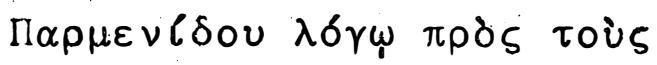

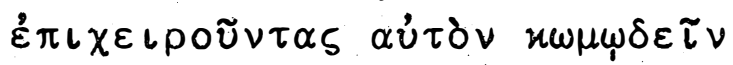

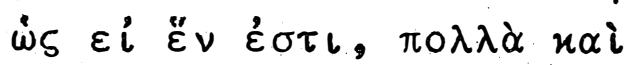
$\gamma \varepsilon \lambda \circ \tilde{\imath} \alpha$ ou $\mu \beta \alpha \ell v \varepsilon \iota \pi \alpha \sigma \chi \varepsilon \iota \nu \quad \tau \tilde{\varphi}$
Simplicius:

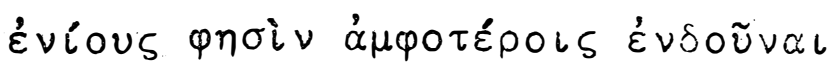

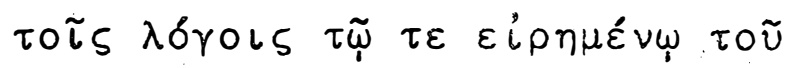

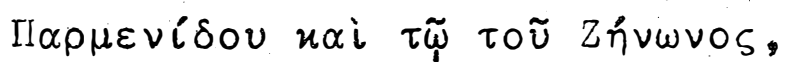

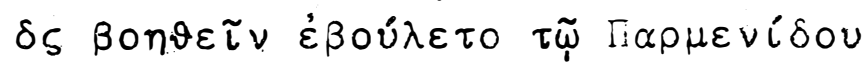

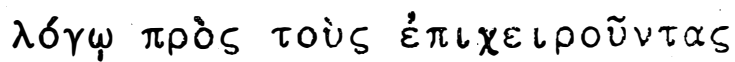

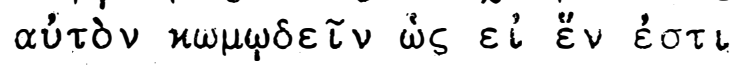




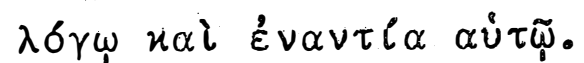

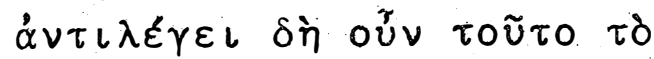

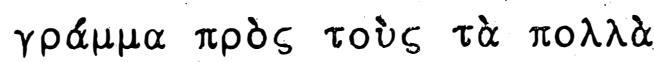
$\lambda \varepsilon \gamma \circ \nu \tau \alpha \varsigma, x \alpha \imath \stackrel{\alpha}{\alpha} \nu \tau \alpha \pi \circ \delta i \delta \omega \sigma \iota$

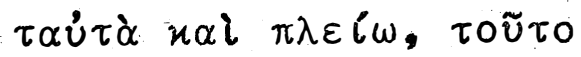

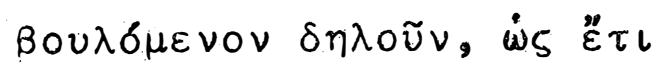
$\gamma \varepsilon \lambda \circ \iota \sigma \tau \varepsilon \rho \alpha \pi \dot{\alpha} \sigma \chi \circ \iota \stackrel{\alpha}{\alpha} \nu \alpha \dot{U} \tau \tilde{\omega} \nu$ $\dot{\eta} \dot{u} \pi \delta \vartheta \varepsilon \sigma \iota \varsigma, \varepsilon \dot{i} \pi \sigma \lambda \lambda \dot{\alpha} \varepsilon \dot{\varepsilon} \sigma \iota \nu$,

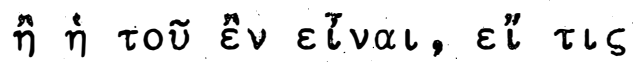

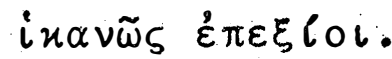

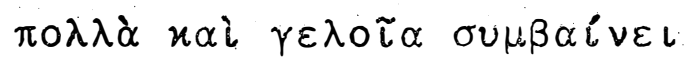

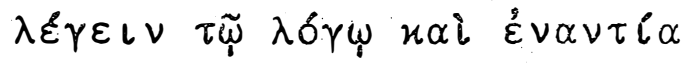

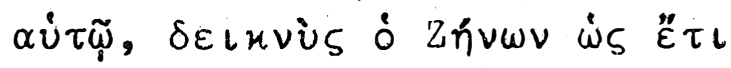
$\gamma \varepsilon \lambda \circ \iota \sigma \tau \varepsilon \rho \alpha \pi \alpha \alpha \sigma \chi \circ \iota \stackrel{\alpha}{\alpha} \nu \alpha \dot{U} \tau \tilde{\omega} \nu \dot{\eta}$

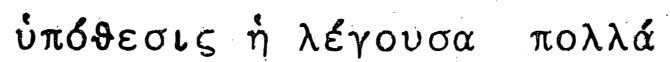
$\varepsilon \dot{\sigma} \sigma \iota \nu \ddot{\eta} \pi \varepsilon \rho \dot{\eta} \tau o \tilde{v} \ddot{\varepsilon} \nu \varepsilon l v \alpha \iota$,

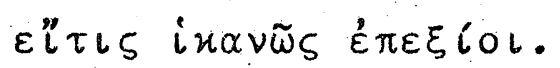

Surely, as soon as we compare the two passages, an independent opinion on the part of Simplicius is out of the question. The extreme similarity of the two testimonies allows only one explanation, and we would arrive at this even if Simplicius did not himself supply it in the immediately following sentence, which Diels unfortunately failed to include in the testimony 29A23 (and which as far as I can see, nobody else has added to the body of evidence that Diels had collected). The sentence states quite

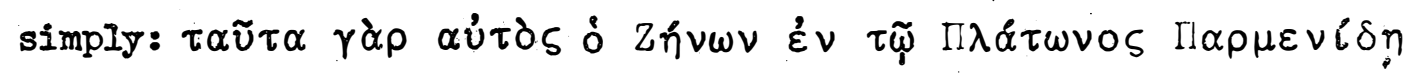

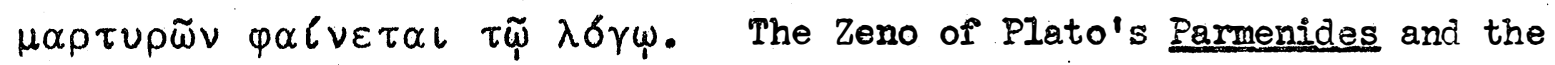
historical Zeno are for Simplicius identical, and the combination of "Zeno himself" with the "divine Plato" (as the Neoplatonists like to call him) would for him suffice to settle the issue. For us the testimony of the Parmenides has no longer the authority which puts it beyond and above all controversy. Simplicius' ready acceptance of it ought to be borne in mind by students of Zeno, not because the testimony A23 itself has had an undue influence on modern views of Zeno, but because Simplicius has preserved the most important fragments, and thus it becomes imperative for us to consider carefully whether the over-all conception of the treatise to which he has committed himself did not guide him in the selection and exegesis of these fragments or indeed even in their presentation. He may 
have shortened some arguments, omitted significant links and minimized material that his conviction allowed him to treat as irrelevant or unintelligible. To come to grips with these problems, we shall study a crucial section of his commentary on the Phrsics in which he finds it necessary to defend his theory (= Plato's hypothesis) about Zeno's purpose against alternative views; for pace H. D. P. Lee (Zeno of Elea, Cambridge, 1936, 7), there were alternative views. Our readers will find on the next page the Greek text of this section; Arabic figures at the end of individual sentences refor to the coments by which I have tried to explain immediately afterwards the rather baffling manoeuvres or Simpliclus, his curious backing and filling. One of our leading authorities on Zeno (Herm. Fränkel) has called the passage "confused," enother (Vlastos) speaks of "clumsiness" but since neither the one nor the other quality is typical of Simplicius' work as comentator, he must have found himself in a particularly embarrassing situation. Confusion, even if Simplicius himself is innocent of 1t, may yet be the state of mind in which the reader finds himself when making his first ecquaintance with the section (if I am mistaken in this supposition I should like to be set right). Our comments may go some way to alleviate the bewilderment. Fortunately Simplicius' verbatim quotations here and slightiy later enable us to reconstruct most of Zeno's original text. We shall after explaining as well as we can Simplicins' contorted reasoning, look at this reconstruction and consider how far we must emaneipate ourselves from Simplicius' presentation if we wish to understand the purport of Zeno's argument. Simplicius is here, as on other occasions, engaged in a polemic against Alexander of Aphrodisias' comentary on Aristotle 's Fhrsias, and elsewhere too he traces Alexander's opinion back to the Fhrsics of Aristotle's immediate pupil Eudemus of Rhodes. 


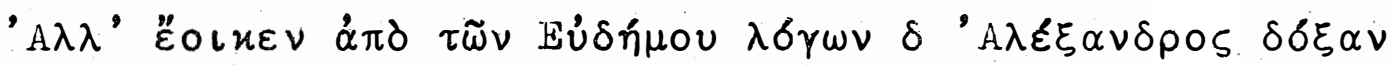

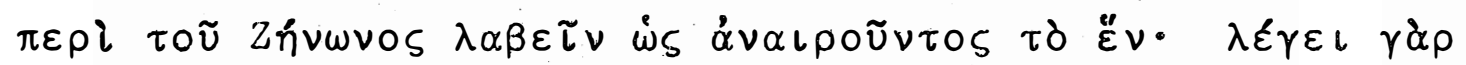

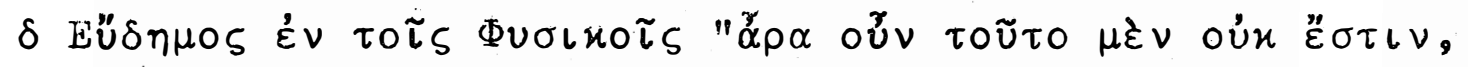

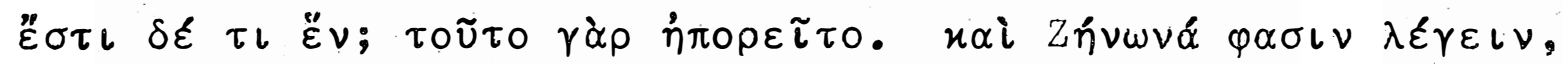

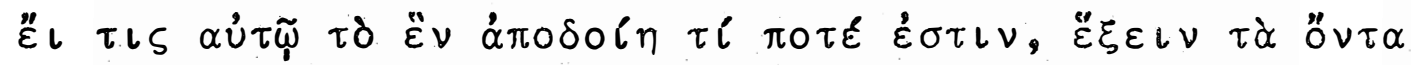

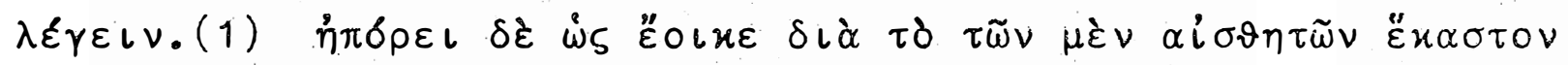

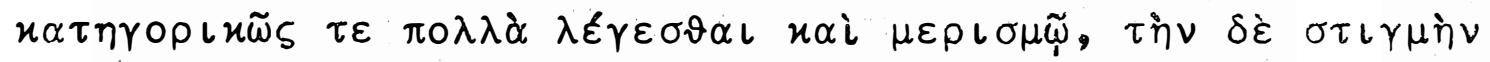

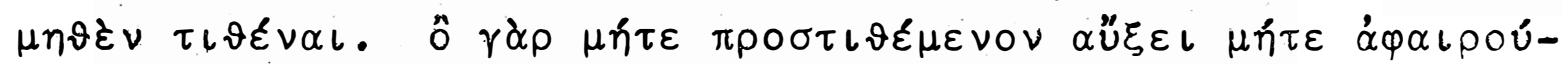

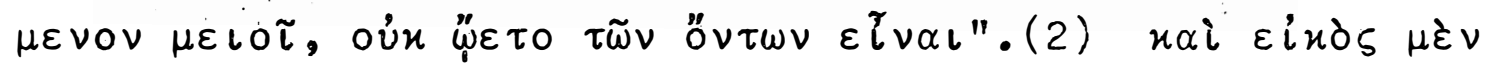

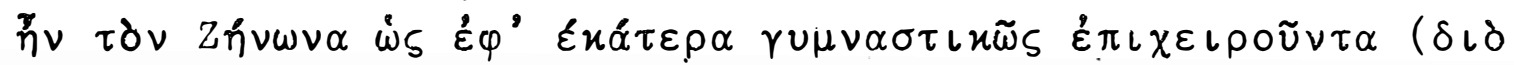

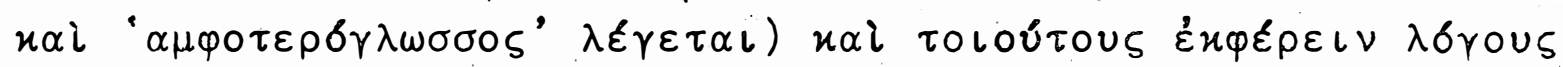

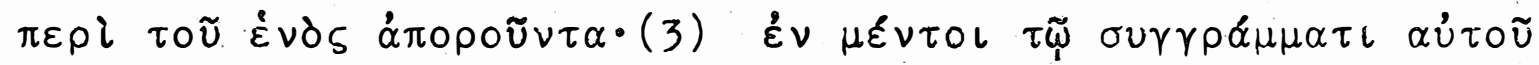

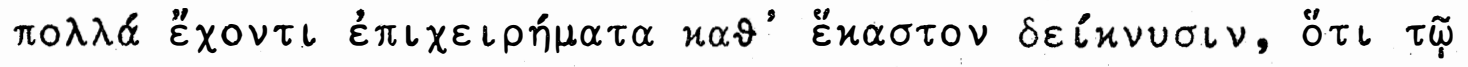

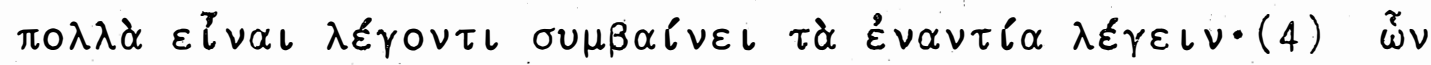

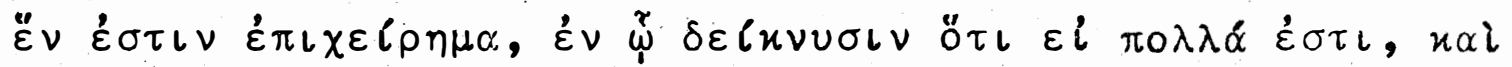

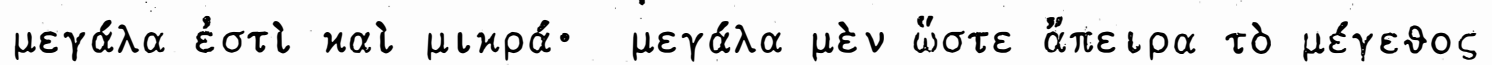

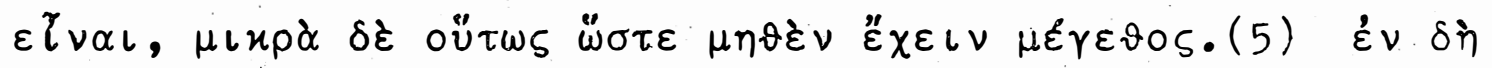

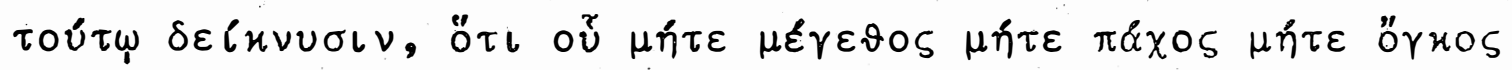

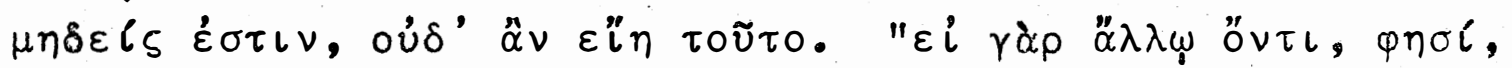

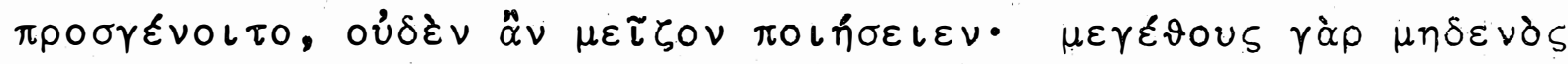

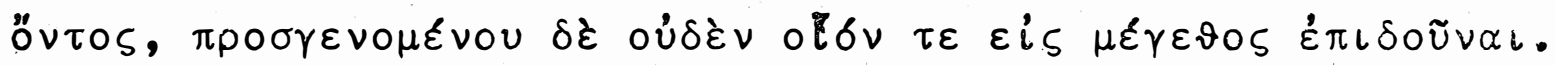

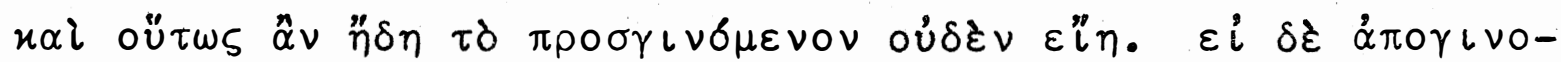

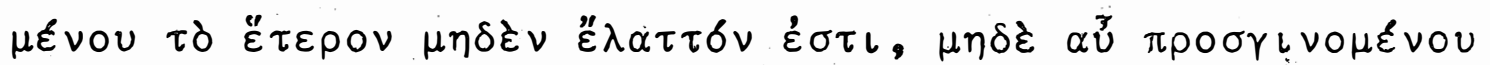

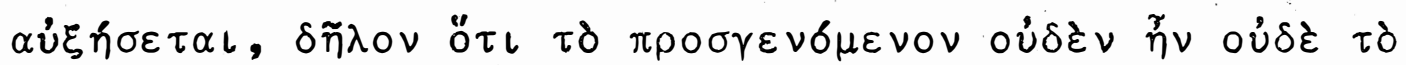

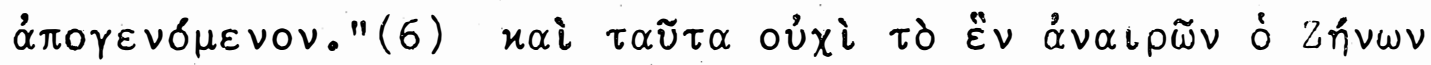

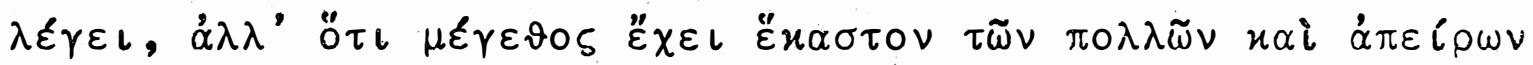

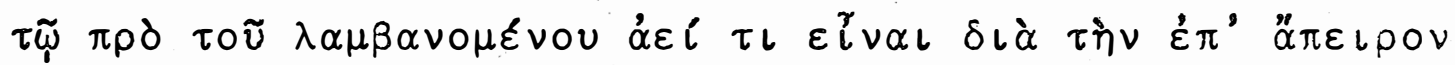

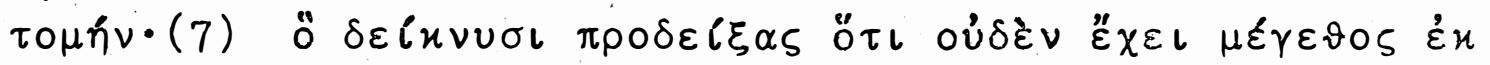

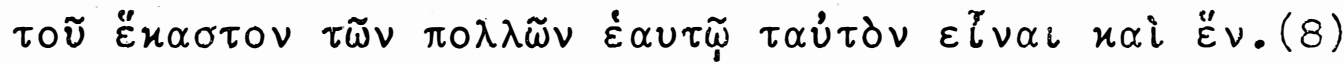

(1) We shall come back to this report about Zeno, which clearly is at variance with Plato's derinition of Zeno's intention.

(2) The former sentence has no value as testimony, since Zeno knew nothing of the Aristotelian categories (to which the adjective 
categorikos refers) and whether or not he was interested in "points," the stigme as here used goes back to Aristotle's exegesis of Zeno's argument in Metaphys. B4.100167-13. The second sentence, even if known to Eudemus from the same source, is nevertheless a reliable summary of Zeno's argurent, which we shall discuss later when we have become acquainted with Zeno's own words and their context.

(3) A half-hearted admission that Zeno may have attacked "the One" as well as "the many."

(4) The familiar melody (S. here works his way back to the "orthodox" opinion).

(5) A summary of $29 B 1$ D. $-K$. We shall study this fragment presently.

$(6)=29 B 2$. As Simplicius himself says, it formed part of the same fragment as 29BI. It has for some time been included in the reconstruction of this fragment and we shall examine it when turning to the fragment.

(7) We know that on the over-all theory to which Simplicius is cormitted, Zeno must on no account attack the One but on the contrary defend it. This must be borne in mind when we read the first clause. As exegesis of Zeno's text it is wrong; for as we shall see, Zeno does present an argument fatal for the hen-or some hen, to put the matter cautiously. If on the other hand Simplicius thinks of Zeno's ultimate purpose, the remaining part of this sentence is wrong, even though it sumarizes Zeno's next step in the argment (see the reconstruction and discussion below). But in truth Zeno has more to say about ta polla. That each of them has "size" is only one half of his argument; the other half of it leads to the opposite conclusion, and as Simplicius himself has assured us, Zeno's purpose was to show up contradictions involved in the assumption that "the many are."

(8) If we combine the content of this and the preceding assertion, the contradiction does emerge. But the preceding sentence remains mis- 
leading and we shall find reasons for suspecting also this last sentence; for while it provides a context for Zeno's attack on the hen, Simplicius' wording renders this attack relatively harmless as being merely incidental in his exposure of "the many."

The reconstruction of Zeno's actual argument which follows, differs only in minor matters from $\mathrm{H}$. Fränkel and Furley ( $I$ follow the latter in marking the steps of the argrment as $a, b, c, d)$ :

a) (What was obviously more than one step is reported by Simplicius

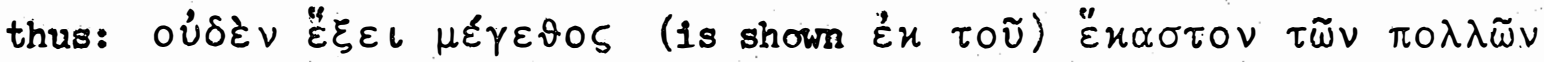

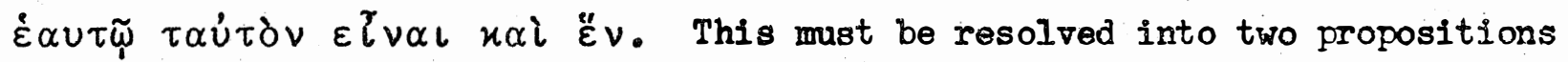
which as soon as they are formulated suggest that something is missing be-

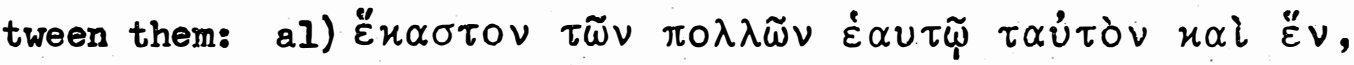

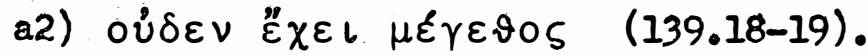

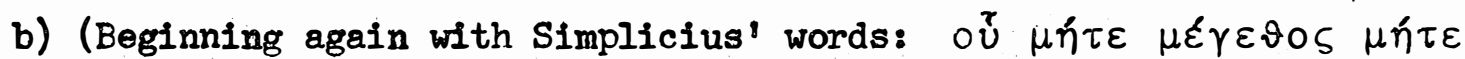

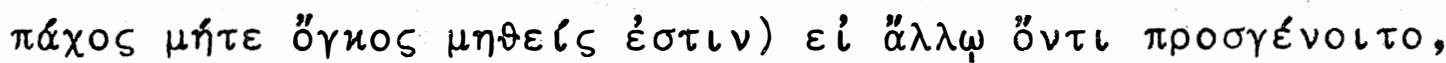

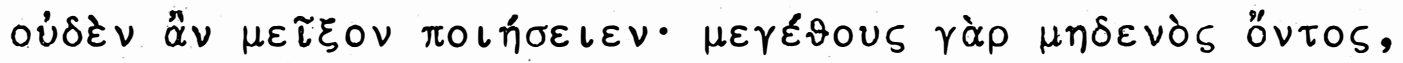

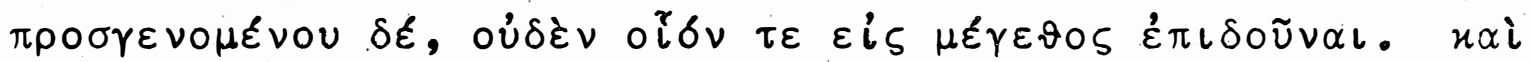

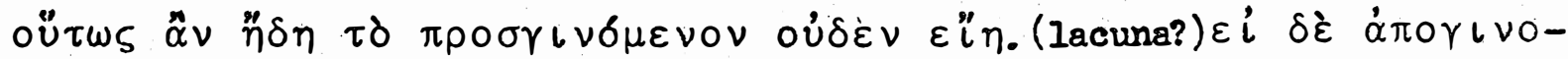

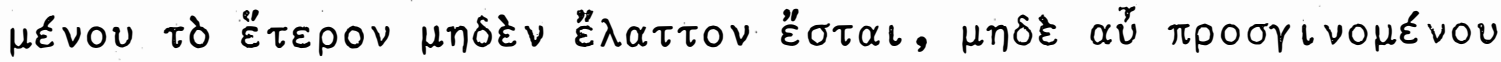

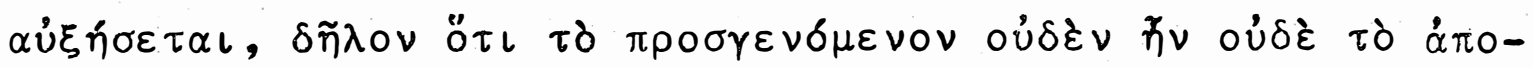

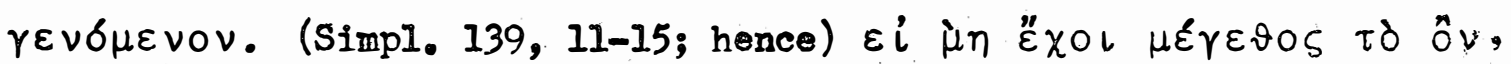

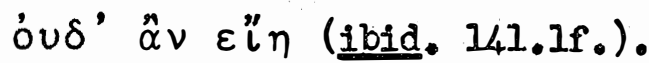

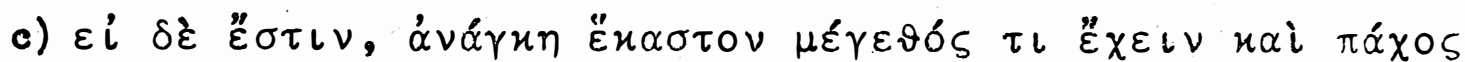

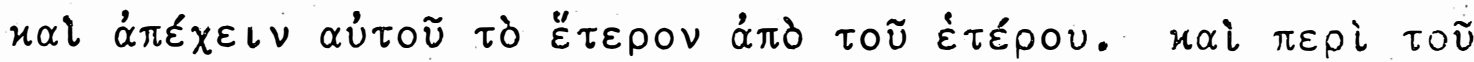

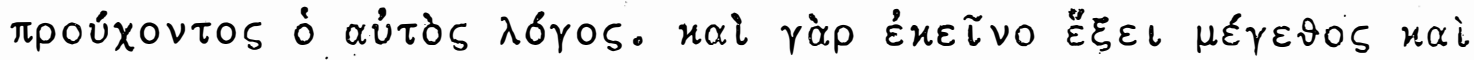

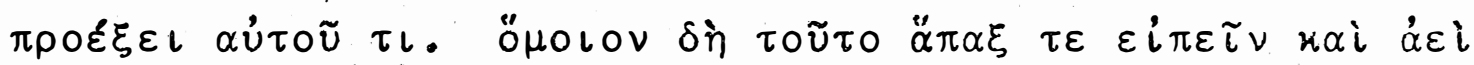

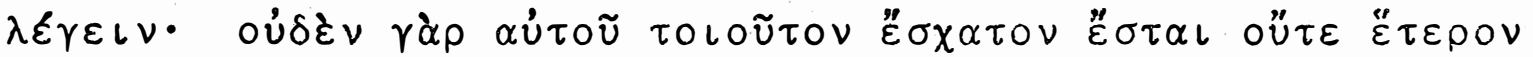

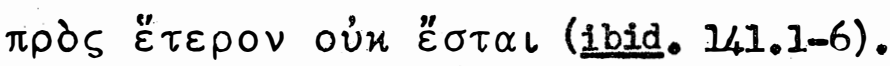

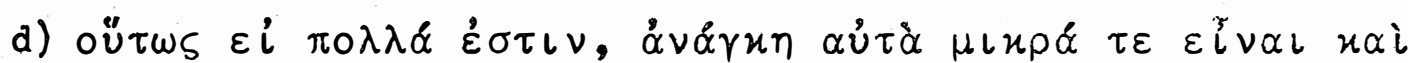

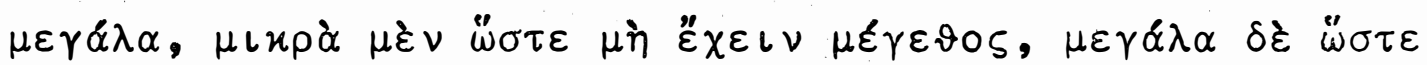
״̈ $\pi \varepsilon \iota \rho \alpha \varepsilon l \nu \alpha \iota$ (ibid., 6-8). 
We feel free to fgnore some uncertainties about details of this reconstruction, nor shall we go into debate about the difficult text in c), since no matter how these sentences are interpreted--whether Fränkel's (A. J. Ph. 63, 1942, 14ff., re-edited in Nege und Formen frihgriech. Denkens) or Vlastos' (Gnomon 31, 1959, 195ff.) exegesis is preferred, our problem is not affected. To put this problem bluntly, does Zeno in the course of his reasoning discredit the One as well as the Many, and are both objectives of equal concern to him? Or is what he says against the One merely a stepping stone on the way to his true and sole objective, the refutation of the Many? We have to take the latter view if in the

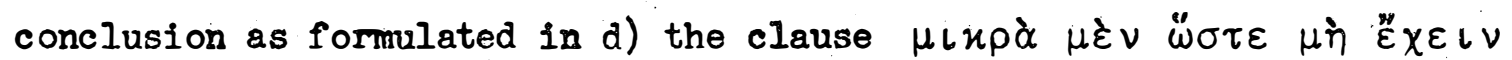
$\mu \varepsilon \gamma \varepsilon \vartheta{ }$ rests on $a$, not on $c$. For if this is the case, the entire sequence a)-d) would deal with "the many" and would bring "opposites" about them to light. More specifically, a) and b) would show that they are "small" and in the end of "no size" at all, c) would prove them to be large, and d) would pull the opposites together. This understanding of the entire argument seems to be suggested by the last sentences of Simplicius in the section fust examined. It would be in accord with Plato's "testimony" in the Parmenides and it has been championed in recent decades by Calogero, Fränkel, Vlastos, Booth, and Furley, a formidable array of authorities. Although most of them accept Plato's testimony, they do not support their interpretation of the fragment by invoking Plato's authority but by specific arguments, which we shall forthwith examine. To anticipate the result of this examination, it is not possible to prove or to refute either of the two theories conclusively, but for the opinion of Alexander and Eudemus that for Zeno $\mu \eta \delta \varepsilon \nu \nu \tilde{\omega} \nu$

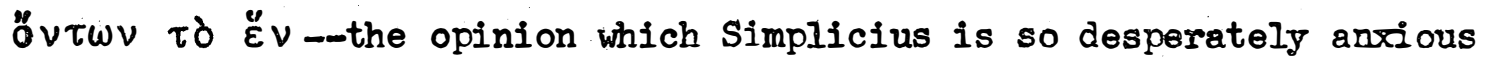
to refute-more than is commonly admitted can be said, and it would be well to give the arguments in favor of it a readier hearing. 
One reason why anyone might hesitate to find for "so small as to have no size" in d) a basis in the immediately preceding sentence of $c$ ) is that while it is easy and perfectly correct to envisage the parts emerging in c) as becoming small and progressively smaller, they yet will never reach the nil magnitude, as Zeno himself seems to recognize by ruling out an eschaton. Surely if Zeno almost immediately after affirming this, spoke of "no size" as final result, he cormitted what Vlastos has rightly called a "logical gaffe." On the other hand "no size" is reached in a), but how? All we know is that "self-identity" and "one" were way stations. While there is no evidence as to how Zeno went from "one" to "no size" and the best hypothesis is to posit the "indivisibility" of the one as the link, other ways too are conceivable, but how could smallness figure in this argument? Yet the "gaffe" of which Zeno is guilty if in passing from c) to d) he allowed smallness to end in "no size" is somehow balanced by the other gaffe which he by general consensus comnitted by allowing the megethos of $\mathrm{c}$ ), which becomes bigger and bigger only in relation to the emerging subdivisions, to end as "infinity." There is a certain symmetry about these two logical errors, and the reader will not fail to perceive this symetry in Zeno's actual phrasing, when in his first conclusion he contents himself with "large" and "small"-both correctly deducible from c)-and then carries both of them to extremes, neither of which is any longer legitimate. Thus serious mistakes are present on either of the two possible interpretations. Less serious may be another

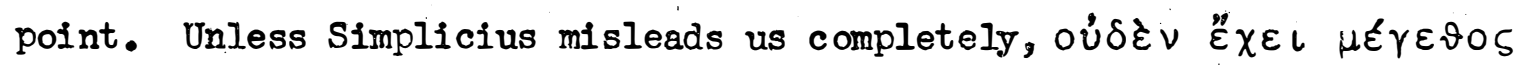
in a2) must mean "nothing has size." This is not the same as the conclusion formulated in $d$ ), where "no size" is by no means asserted of all polla-or if it is asserted, this would be one more gaffe; it sureiy is more charitable to understand Zeno here as allowing entities to be large 
and small and introducing "no size" as an extreme of "smali" (we need not ask of what it is predicated; presumably any such item would cesse to "be"). Who likes may notice that while Zeno's actual text in d) expresses "no size" by mē.megethos, Simplicius' report renders this point (in the sentence before 5) by mëden, megethos, a trifling inaccuracy no doubt, and yet it results in increasing the similarity between this clause in d) and the words ouden, megethos in his paraphrase of a) at the very end of the section we have presented.

Small and of little woight as this observation is, it yet may serve as a warning against delivering ourselves too readily into the hands of Simplicius. This has some bearing on the next question I wish to raise. According to Simplicius in the section copied above Zeno showed in a) that "each of the many" is identical with itself, is one and has no size (even if for the last proposition he changed his phrasing slightly) while in c) he showed that "each of the many has size." Following closely upon one another, these two items in his report favor or even suggest the interpretation of the entire fragment which contemporary scholars have adopted. The symmetry makes this interpretation almost inevitable, especially since in both sentences we find the words hekaston ton pollon. Still the symmetry may only be apparent. We have Zeno's own text only for c), not for a) and when looking at c) we find in it the word hekaston but not tōn pollōn. Thinking that they were germane to Zeno's meaning, Simplicius may have extracted these two words from d); yet whatever prompted him, it would surely be rash if on his authority we assumed the words hekaston ton polion actually to occur in a). Whether or not Zeno spoke of "the many" in a) must remain an open question. An affirmative answer has been given so far on the basis of Simplicius' report, probably

1. Therefore Herm. Fränkel, 10c, cit. 15 and $17 n_{0} 46$ has transferred the words so as to place hekeston ton pollon inmediately after megethos. This makes the symmetry perfect. 
as combined with Plato's testimony in the Farmenides. Are there really no alternatives? Too little attention is paid by Simplicius and by and large also by modern scholars to b) and the opening words of $c$ ). They show a considerable concern with einai. The argument by which in $b$ ) what has no size is ruled out of existence is decidedly elaborate, and as soon as einai is reintroduced at the beginning of c) we evidently find ourselves on a new basis for the ensuing argumentation. Thus it would -exempli gratia-be conceivable that Zeno's entire argument, focusing on "being and what is" would begin by proving whatever "is" to be "one," then argue the "one"-or, perhaps more correctly, whatever is "one"-out

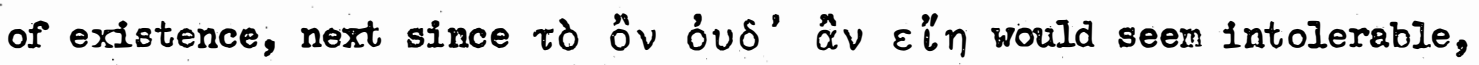
c) would begin by positing the opposite of what proved fatal in a) and b), would investigate the new position, and in the end in a) we would find ourselves once more deadlocked, since if being is "many," there would emerge the typical contradictions. Actually Zeno would on this hypothesis have practiced his habitual demonstration of ta enantia not only for "the many" but he would in a more comprehensive manner have proved first the assumption of a "one" to be impossible and then meted out the same fate to the assumption of the polla (or, more exactly of the existence of ta polla; for as I wish to suggest, einal and on are important throughout the argument). I do not at all maintain that the reconstruction here attempted must be correct; still less do I wish to discourage other attempts. On the contrary I should encourage them; for while none may be cogent, the thesis which so far has enjoyed a monopoly, scil. that from the first word to the last Zeno's concern is with "the many" ought to be put to a more severe test. It may be true but it is dangerous to take its truth for granted.

Another difficulty for the prevailing interpretation of this fragnent may be found in a passage of Simplicius separated by barely a page from 
that quoted in full above. Here (in Phys. 14l.Iff.; esp. 9ff.) Simplicius' Immediate objective is to prove Zeno's use of "dichotomy." To establish his point he quotes two arguments by which Zeno proved the "quantitative infiniten in the sense of an infinite multitude arising in the progress of division. Having adduced $B 3$ he proceeds to the argument which engages

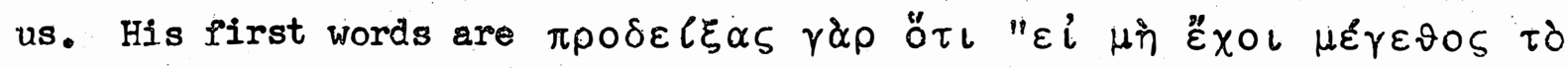
ô้ text of c) and d) as copied by us above. After finishing the quotation Simplicius feels moved once more to protest against Alexander's allegation that Zeno wished to refute the "One." His real purpose was to "strengthen Parmenides doctrine" about the One and to refute "the many" through "the

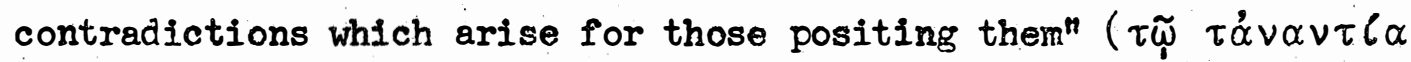

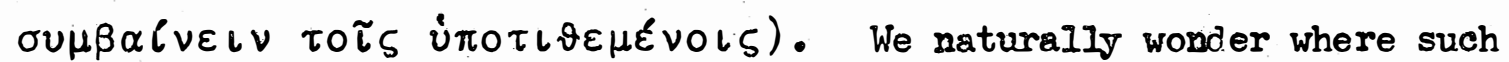
a contradiction here materializes. Obviously it is formulated in d) but does c) alone this time suffice as basis for the conclusion drawn in d)? inclination would be to think so. As an alternative we might suppose that Zeno being primarily concerned with the subject of dichotony allows himself some carelessness in the matter of "the contradictions." Also a friendly critic has suggested to me that the words introduced by prodeixas should be taken into consideration and that combined with $c$ ) they would produce the contradiction. Consideration should certainily be given to this possibility, even though without this brief introduction the first three words of c) would be difficult to understand and this may be the reason why simplicius provides the introduction. Moreover worded as it is, the introduction would hardly furnish the best basis for "small so as to have no size" in d), for apart from referring to to on, not to "the many," it takes "no size" for granted and acquaints us with some dire consequences of this condition. What simplicius reports two pages earlier and what for us is a), scil. "nothing has size" because 
"each of the many is....one" would seem to prepare this clause in d) better. Still it may not be for us to adviso simplicius about the most effective procedure.

Thus while the prevailing interpretation of the entire fragment from a) to d) cannot claim to hold all tmup cards and a good deal may be said In favor of other approaches, certainty eludes us. Still no matter whether whother Zeno in the first half of the fragment made it his object to invalidate the hon and in the second ta polla or whether his objective remained from the beginning to the end to show the contradictions inherent in ta polla, a serious problem remains. For on either assumption the hen is attacked and shown to be nothing (or not to "be"). Now who wishes may boldly discount Eudemis' statement about Zeno's ignorance and aporia concerning the hen, since Eudemus reports from hearsay and may have misunderstood something. We may similarly dismiss Plato's testimony in the

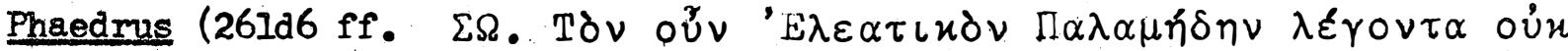

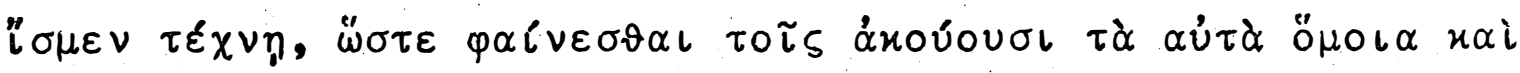

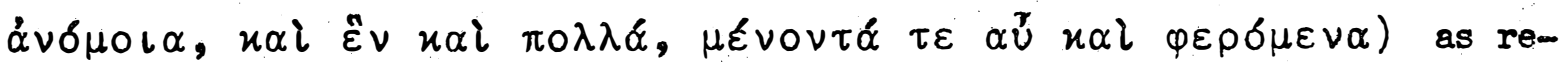
flecting only "impressions" of the audience. The reasoning against the hen in our fragment cannot be disputed away, and whether or not it was merely a step on the way to something more important, it is difficult to explain if Zeno wrote his treatise to defend the hen of Parmenides. Booth in his paper (Phronesis 3, cited on our first pages) has drawn attention to this embarrassing problem. The only escape from the embarrassment is to insist on a fundamental difference between this hen and the all embracing, solitary hen of Parmenides. Yet even on this hypothesis, how odd would it be that Zeno in his polemic against ta polla should discredit 2 hen and prove its non-existence? His readers may in any case have been baffled; by this turn he would gratuitously increase their confusion. 
For how would people who had no schooling in the posachos legetai distinguish one hen from the other? How would they realize that if this hen and ta polla are discredited, the only truth left is the (alleged) Parmenidean conception of the hen. Or that if any megethos qua syneches is divisible ad infinitrm, they must conceive a hen which (for the reasons stated by Parmenides in B8.22-5) is at the same time syneches and adiaireton? And, to continue in this vein, how were they from Zeno's analysis of movement and the difficulties he discovered in it to proceed in their minos to the concept of ekineton (cf. Parm. B8.26, 38) as essential for the One? or from the difficulties of topos and of being in a topos arrive at the idea of something-presumably again the one-resting in the same place and by -or in-itself (B8.29)? In the words of another Platonic dialogue

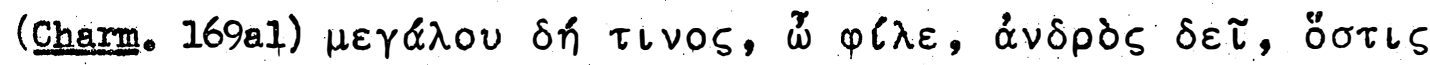

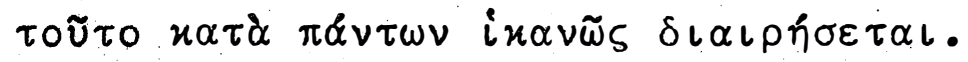

But perhaps our disquisitions and worries are unnecessary. Plato himself provides the solution; for as we have seen, Socrates and Zeno agree (differing only on a minor aspect of the matter) in admitting the difficult and deceptive quality of Zeno's treatise. To penetrate to Zeno's true meaning and realize the basic identity of his and Parmenides' position is, Socrates says, "above us others" (128b5f.). Are we then to suppose that most readers being puzzled by the arguments were perhaps entertained or spellbound but unable to see the intention behind all of them-until Plato appeared, playing in this instance the role of the negas aner being capable of distinguishing and analyzing what had proved too mech for others? An alternative explanation would be that, discounting the anecdotical embroidery of Parm. 128d6ff. wo think of the treatise as originally composed for a group of faithful Parmenideans whom the identical intention of all refutations and paradoxes would not escape. 
Whaterer the solution, acceptance of Plato's testimony in the Parmenides raises more problems than has comnonly been realized. In spite of these problems Plato's divinatio may yet have hit the truth but to have this confldence involves an act of faith. If anyone wonders what other theory we-with our very limited means-may put forward regarding leno's treatise, he may take notice of the fact that in the Phaedrus Plato mentions Zeno not in the company of other philosophers but of rhetoricians like Thrasymachus, Thepdorus and Gorgias. We instinctively rebel against finding him classed with men whose ambition was to establish a hold on people's minds by dazzling them, swaying them, and if necessary even deceiving them; for we are wont to consider Zeno a thinker of high order and originality whose discoveries have been called immeasurably prafound and whose problems and dilenmss deeply influenced the subsequent developments of philosophy. St11l, granting all of this and admitting also that Plato in the Pamenides had every right to wonder about the "Intention" of Zeno's treatise-for whatever is written reflects some kind of intention on the part of its author-Plato may jet prejudice the inquiry by expecting the intention to relate to a definite philosophical position and by insisting that the conclusions of all individual argments converged in this direction. Zeno, to judge from what little we know, seems to delight in intellectual experimentation, in the discovery and exploitation of new argunentative methods. Problems, dilemnas, paradoxes, equally defensible alternatives may have fascinated him more for their own sake than for that of a resolution and positive "results." In the devising of new methods and argumentative techniques he remains a pioneer; here lies his mein achievement. That for the application of this unique gift he found a fertile ground in the con temporary philosophical situation, or to be specific, in Parmenides' challenge to all earlier physikol would be natural even if Elea had not been his eity and if citical reactions to Parmenides had not kept the issues alive. 
The discovery of infinite divisibility alone opened up possibilities as inexhaustible in their application as were the increasingly smaller segments brought to light by every aperation which employed this new idea. Should all use that Zeno himself made of it have served one and tho same end? Must even the question about the millet seeds, allegediy addressed to Protagoras, be constructed as a support of Parmenides? Zeno, I repeat, gives the impression of having enjoyed the game. If it had serious implications, so much the better. He may well head the long line of those who professed themselves able to present two mutually contradictory logof on every subject (even though we do not in every instance know his second answer and he may indeed sometimes have thought one starting answer sufficient).

After all this has been said, it still remains possible-but no more than possible-that he readily placed all resources of his inventimess at the service of Parmenides? thesis. He may have done so because he was honestly convinced of its truth or because it was attractive to defenc something that went against common sense and everybody's natural inclinam tion. Who after twenty four centuries and on the basis of what littie we know may venture to define his motivation? And who can even assure us that the true explanation of the impulse behixd his intellectual adventures may not elude us altogether? 